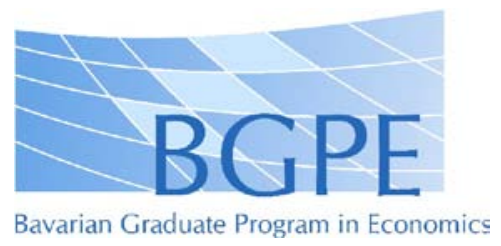

BGPE Discussion Paper

No. 118

\title{
Testing for Parameter Stability in DSGE Models. The Case of France, Germany, Italy, and Spain
}

\section{Jürgen Jerger \\ Oke Röhe}

April 2012

\section{ISSN 1863-5733}

Editor: Prof. Regina T. Riphahn, Ph.D.

Friedrich-Alexander-University Erlangen-Nuremberg

(c) Jürgen Jerger, Oke Röhe 


\title{
Testing for Parameter Stability in DSGE Models. The Cases of France, Germany, Italy, and Spain ${ }^{1}$
}

\author{
Jürgen Jerger ${ }^{2}$ \\ University of Regensburg and Osteuropa-Institut Regensburg
}

Oke Röhe ${ }^{3}$

University of Regensburg

April 2012

\footnotetext{
${ }^{1}$ We are grateful for the comments of David N. DeJong, the help with the estimation programs provided by Peter N. Ireland, the provision of the ESS code by Barbara Rossi, as well as the conference and seminar feedback from Bratislava, Kiel, Münster, and Regensburg.

${ }^{2}$ Jürgen Jerger, Institute for East European Studies, Regensburg and University of Regensburg, Universitätsstr. 31, 93053 Regensburg, Germany. Email: juergen.jerger@wiwi.uniregensburg.de. Phone: ++49-(0)941-9432697.

${ }^{3}$ Oke Röhe, University of Regensburg, Universitätsstr. 31, 93053 Regensburg, Germany. Email: oke.roehe@wiwi.uni-regensburg.de. Phone: ++49-(0)941-9432720.
} 


\begin{abstract}
We estimate a New Keynesian DSGE model on French, German, Italian, and Spanish data. The main aim of this paper is to check for the respective sets of parameters that are stable over time, making use of the ESS procedure („Estimate of Set of Stable parameters") developed by Inoue and Rossi (2011). This new econometric technique allows to address the stability properties of each single parameter in a DSGE model separately. In the case of France, Germany, and Italy our results point to structural breaks after the beginning of the second stage of EMU in the mid-nineties, while the estimates for Spain show a significant break just before the start of the third stage in 1998. Specifically, there are significant changes in monetary policy behavior for France, Italy, and Spain, while monetary policy in Germany seems to be stable over time.
\end{abstract}

Keywords: DSGE, EMU, Monetary Policy, Structural Breaks JEL Classification E31, E32, E52 


\section{Introduction}

Dynamic stochastic general equilibrium (DSGE) models have become a standard tool of modern macroeconometrics. The attractiveness of this class of models lies in the symbiosis of theoretical models and the forefront of macroeconometric analysis. As outlined e.g. in DeJong and Dave (2007) and Fernández-Villaverde (2010) the combination of rich structural models, novel solution algorithms and powerful simulation and estimation techniques lead to a very active and progressive discipline changing the way we think about macroeconomic modeling and economic policy advice. In this paper, we contribute to this area of research by employing an econometric technique, recently introduced by Inoue and Rossi (2011), to test for parameter stability in a New Keynesian model estimated for the four largest countries of the European Monetary Union (EMU): France, Germany, Italy, and Spain. By doing so, we add to a vast literature that developed around the topic of economic integration within Europe. One of the important aspects of this ongoing and gradual integration process was the introduction of a common monetary policy in the EMU. Evaluating the overall macroeconomic performance in 2008, the European Commission (2008) summarizes that the record after almost one decade of the EMU looks quite favorable. More detailed analyses of European economic integration can be grouped into four distinct strands of literature. The first looks at the implications of a common currency for other economic institutions like regulation or wage setting; see e.g. von Hagen (1999), Cukierman and Lippi (2001), Jerger (2002) and Fratzscher and Stracca (2009). A second one analyzes the (change of) different transmission channels of monetary policy (van Aarle et al., 2001; Angeloni and Ehrmann, 2006; Jarocinski, 2010; Hughes Hallett and Richter, 2009). Thirdly, the availability of micro data, especially for loans and prices, led to a large literature that usually identifies statistically and economically significant convergence across countries due to monetary union (Beck and Weber, 2005; Popov and Ongena, 2011). A fourth and relatively recent literature uses dynamic stochastic general equilibrium (DSGE) models to characterize the euro area or the economies in this region within some well-defined theoretical framework (see, e.g., Lee, 2009; Milani, 2009; Reis, 2009).

Here, we contribute to the last strand and add the dimensions parameter stability over time and cross country comparisons. To do so we employ the ESS procedure („Estimate of Set of Stable parameters“) introduced by Inoue and Rossi (2011). This allows to pin down the subset of parameters of a model that are stable for an unknown break date. Following Inoue and Rossi (2011, p. 9), „.. our analysis focuses on the 
situation in which there is a single, unanticipated and once for all shift in some of the parameters of the structural model at an unknown time, and in which there is an immediate convergence to a rational-expectations equilibrium after the regime change."

In the case of France, Germany, and Italy our results point to structural breaks after the beginning of the second stage of EMU in the mid-nineties, while the estimates for Spain show a significant break just before the start of the third stage in 1998. Specifically, there are significant changes in monetary policy behavior for France, Italy, and Spain, while monetary policy in Germany seems to be stable over time. We also find significant declines in capital and price adjustment costs in France, Italy, and Spain.

The rest of the paper is structured as follows. Section 2 presents the model. Data issues are discussed in section 3, whereas the ESS procedure is outlined in section 4. The results are presented and interpreted in section 5. Section 6 concludes.

\section{The Model}

\section{$2.1 \quad$ Overview}

The model we use for France, Germany, Italy, and Spain is similar to the standard closed-economy New Keynesian framework developed in Ireland (2003). The model economy features a representative household, a representative finished goods-producing firm, a continuum of intermediate goods-producing firms indexed by $i \in[0,1]$, and a monetary policy authority. During each period $t=0,1,2, \ldots$, the intermediate goods

producing firms produce a distinct, perishable intermediate good, also indexed by $i \in[0,1]$. The solution requires these firms to be treated symmetrically.

Before describing the model it is necessary to comment on the fact that we apply a closed-economy model to indisputably open economies. The most important reason is the obvious fact that we get around the notorious difficulties of modeling exchange rates and their implications for bilateral trade flows. In the present context, we are not particularly interested in those, since the exchange rate consequences of EMU on member states are pretty clear. Furthermore, openness makes it very difficult to characterize the process of capital formation that is a central part of the present model; see also the discussion by DiCecio and Nelson (2007) who apply a closed-economy model to the UK as well as the remarks of Obstfeld (2002) and Neiss and Nelson (2003) concerning closed-economy models.

We now proceed to characterize the decisions taken by households and firms before 
looking at the behavior of the monetary authority and sketching the solution of the model.

\subsection{Households}

The representative household enters period $t$ holding $M_{t-1}, B_{t-1}$, and $K_{t}$ units of money, one-period bonds, and physical capital rented to the intermediate goods sector, respectively. In addition to this endowment, the household receives a lump sum transfer $T_{t}$ from the monetary authority at the beginning of period $t$. The household receives $W_{t} h_{t}$ units of labor income, with $W_{t}$ denoting the nominal wage rate and $h_{t}$ working hours; $K_{t} Q_{t}$ in capital income, where $Q_{t}$ represents the rental rate for capital and $K_{t}$ household's capital supply; and a nominal dividend $D_{t}$ from the intermediate goods producing firm. Each source of income is measured in units of money.

The household uses its funds to purchase new bonds at the nominal cost $B_{t} / r_{t}$, where $r_{t}$ denotes the gross nominal interest rate between time periods, or output from the final goods sector at price $P_{t}$. This good can be used for consumption $C_{t}$ or investment $I_{t}$. In the latter case, quadratic capital adjustment cost given by

$$
\frac{\phi_{K}}{2}\left(\frac{K_{t+1}}{K_{t}}-1\right)^{2} K_{t}
$$

accrue to the household, where $\phi_{K} \geq 0$ governs the size of these adjustment costs. The capital accumulation process is given by

$$
K_{t+1}=(1-\delta) K_{t}+x_{t} I_{t}
$$

with $0<\delta<1$ denoting the rate of depreciation and $x_{t}$ representing a shock to the efficiency of investment. This shock is specified as

$$
\ln \left(x_{t}\right)=\rho_{x} \ln \left(x_{t-1}\right)+\varepsilon_{x t}
$$

with $0<\rho_{x}<1$ and $\varepsilon_{x t} \sim N\left(0, \sigma_{x}^{2}\right)$ as introduced by Greenwood, Hercowitz and Huffman (1988).

The budget constraint of the representative household is given by

$$
\frac{M_{t-1}+T_{t}+B_{t-1}+W_{t} h_{t}+Q_{t} K_{t}+D_{t}}{P_{t}} \geq C_{t}+I_{t}+\frac{\phi_{K}}{2}\left(\frac{K_{t+1}}{K_{t}}-1\right)^{2} K_{t}+\frac{B_{t} / r_{t}+M_{t}}{P_{t}}
$$


Facing this constraint, the household maximizes the stream of expected utility

$$
E \sum_{t=0}^{\infty} \beta^{t}\left\{a_{t}[\gamma /(\gamma-1)] \ln \left[C_{t}^{(\gamma-1) / \gamma}+e_{t}^{1 / \gamma}\left(M_{t} / P_{t}\right)^{(\gamma-1) / \gamma}\right]+\eta \ln \left(1-h_{t}\right)\right\}
$$

where $0<\beta<1$ is a discount factor and $\eta>0$ measures the relative weight of leisure. Further, it can be easily shown that $-\gamma$ is the interest rate elasticity of money demand. The utility function (3) contains two preference shocks, which are both assumed to follow an autoregressive process. More specifically,

$$
\ln \left(a_{t}\right)=\rho_{a} \ln \left(a_{t-1}\right)+\varepsilon_{a t},
$$

with $0<\rho_{a}<1$ and $\varepsilon_{a t} \sim N\left(0, \sigma_{a}^{2}\right)$ denotes an IS shock (McCallum and Nelson, 1999), whereas

$$
\ln \left(e_{t}\right)=\left(1-\rho_{e}\right) \ln (e)+\rho_{e} \ln \left(e_{t-1}\right)+\varepsilon_{e t}
$$

with $0<\rho_{e}<1, e>0$ and $\varepsilon_{e t} \sim N\left(0, \sigma_{e}^{2}\right)$ represents a money demand shock.

\section{$2.3 \quad$ Firms}

The final good $Y_{t}$ is produced by a firm acting in a perfectly competitive market, which combines the intermediate goods $Y_{t}(i)$ according to

$$
Y_{t} \leq\left[\int_{0}^{1} Y_{t}(i)^{(\theta-1) / \theta} d i\right]^{\theta /(\theta-1)}
$$

where $\theta>1$ represents the elasticity of substitution between intermediate goods $Y_{t}(i)$. With $P_{t}(i)$ denoting the price of intermediate good $i$, profit maximization leads to the following demand function for intermediate goods

$$
Y_{t}(i)=\left[\frac{P_{t}(i)}{P_{t}}\right]^{-\theta} Y_{t}
$$

where

$$
P_{t}=\left[\int_{0}^{1} P_{t}(i)^{1-\theta} d i\right]^{1 /(1-\theta)} .
$$

Each intermediate good $i$ is produced by a single monopolistically competitive firm 
according to the constant returns to scale technology

$$
Y_{t}(i) \leq K_{t}(i)^{\alpha}\left[z_{t} h_{t}(i)\right]^{1-\alpha}
$$

where $1>\alpha>0$ represents the elasticity of output with respect to capital. The technology shock $z_{t}$ follows the autoregressive process

$$
\ln \left(z_{t}\right)=\left(1-\rho_{z}\right) \ln (z)+\rho_{z} \ln \left(z_{t-1}\right)+\varepsilon_{z t}
$$

with $1>\rho_{z}>0, z>0$, and $\varepsilon_{z t} \sim N\left(0, \sigma_{z}^{2}\right)$. As it is clear from (6), each firm $i$ exerts some market power, but is assumed to act as a price taker in the factor markets. Furthermore, the adjustment of its nominal price $P_{t}(i)$ is assumed to be costly, where the cost function is convex in the size of the price adjustment. More specifically, following Rotemberg (1982), these costs are specified as

$$
\frac{\phi_{P}}{2}\left[\frac{P_{t}(i)}{\pi P_{t-1}(i)}-1\right]^{2} Y_{t}
$$

where $\phi_{P} \geq 0$ governs the size of price adjustment costs and $\pi$ denotes the gross steadystate rate of inflation targeted by the monetary authority (described below). Due to the convexity of (8), the firm's problem becomes dynamic. It chooses $h_{t}(i), K_{t}(i), Y_{t}(i)$, and $P_{t}(i)$ to maximize its total market value

$$
E \sum_{t=0}^{\infty} \beta^{t} \lambda_{t}\left[D_{t}(i) / P_{t}\right]
$$

where $\lambda_{t}$ measures the period $t$ marginal utility to the representative household provided by an additional euro of profits. These are distributed to the household as dividends, defined in real terms by

$$
\frac{D_{t}(i)}{P_{t}}=\left[\frac{P_{t}(i)}{P_{t}}\right] Y_{t}(i)-\frac{W_{t} h_{t}(i)+Q_{t} K_{t}(i)}{P_{t}}-\frac{\phi_{P}}{2}\left[\frac{P_{t}(i)}{\pi P_{t-1}(i)}-1\right]^{2} Y_{t}
$$




\subsection{Monetary policy}

Similar to Ireland (2001) monetary policy is represented by a generalized Taylor rule of the form

$$
\ln \left(r_{t} / r\right)=\omega_{\mu} \ln \left(\mu_{t} / \mu\right)+\omega_{\pi} \ln \left(\pi_{t} / \pi\right)+\omega_{y} \ln \left(y_{t} / y\right)+\ln \left(v_{t}\right)
$$

encompassing the standard Taylor (1993) rule (when $\omega_{\mu}=0$ ), where the monetary authority changes interest rates in response to inflation and output deviations. If $\omega_{\mu}$ is non-zero, monetary policy can be considered to influence a linear combination of the interest rate $r_{t}$ and money growth $\mu_{t}=M_{t} / M_{t-1}$ in response to deviations of inflation $\pi_{t}$ and detrended output $y_{t}$ from their steady-state values. Two alternative interpretations are that the central bank may simply respond to money growth because a) it wishes to protect the economy from the effects of money demand shocks or b) because money growth is a predictor of future inflation; see Christensen and Dib (2008).

The monetary policy shock $v_{t}$ follows the autoregressive process

$$
\ln \left(v_{t}\right)=\rho_{v} \ln \left(v_{t-1}\right)+\varepsilon_{v t},
$$

where $0<\rho_{v}<1$ and $\varepsilon_{v t} \sim N\left(0, \sigma_{v}^{2}\right)$.

It is important to note that this characterization of the monetary authority does not even ask the question of optimal monetary policy. Being aware that there are a lot of alternative specifications of monetary reaction functions and that it might be doubtful to assume an identical specification of the monetary policy function for the four economies under consideration we would like to stress that we are much more interested in examining the statistical relationship between short term interest rates, inflation, money growth and the output gap in four different countries than in issues regarding the specification of monetary policy.

\subsection{Solution and Estimation}

The model is characterized by a set of nonlinear difference equations, namely the firstorder conditions for the three agents' problems, the laws of motion for the five exogenous shocks (2), (4), (5), (7), and (10) and the monetary policy rule (9). Two additional steps are required to close the model. First, in order to get from sectoral to aggregate variables, symmetric behavior within the intermediate sector is assumed, implying 
$P_{t}(i)=P_{t}, Y_{t}(i)=Y_{t}, h_{t}(i)=h_{t}, K_{t}(i)=K_{t}$, and $D_{t}(i)=D_{t}$ for all $i \in[0,1]$. Second, the market clearing conditions for both the money market $M_{t}=M_{t-1}+T_{t}$ and the bond market $B_{t}=B_{t-1}=0$ must hold for all $t=0,1,2 \ldots$.

Since the model is nonlinear, no exact closed-form solution exists in general. An approximate one is obtained by calculating the stationary representation of the model, computing the steady state, log-linearizing the system around the steady state, and then applying the method of Blanchard and Kahn (1980) to solve linear difference models under rational expectations. The solution takes on the form of a state space representation with a state equation

$$
\mathrm{s}_{\mathrm{t}}=\mathrm{A} \mathrm{s}_{\mathrm{t}-1}+\mathrm{B} \varepsilon_{t}
$$

and an observation equation

$$
\mathbf{f}_{\mathrm{t}}=\mathrm{Cs}_{\mathrm{t}}
$$

where $\mathbf{s}_{\mathbf{t}}$ contains the model's state variables including the current capital stock, lagged real balances, and the five exogenous shocks. The vector $\varepsilon_{t}$ consists of the mutually as well as serially uncorrelated innovations $\varepsilon_{a t}, \varepsilon_{e t}, \varepsilon_{x t}, \varepsilon_{z t}, \varepsilon_{v t}$ and $\mathbf{f}_{\mathbf{t}}$ comprises the model's flow variables including current values of consumption, investment, inflation and the nominal interest rate. The matrices $\mathbf{A}, \mathbf{B}$, and $\mathbf{C}$ contain (functions of) the „deep" as well as the policy rule parameters of the model. These parameters are estimated using maximum likelihood. As outlined in Canova (2007, p. 123), “... the likelihood function of a state space model can be conveniently expressed in terms of one-step-ahead forecast errors, conditional on the initial observations, and of their recursive variance, both of which can be obtained with the Kalman filter." Because likelihoods can have several peaks we use multiple starting values as well as different numerical search algorithms ${ }^{1}$ to circumvent stalling at a local peak.

\section{Data}

To estimate the structural parameters of the model we use French, German, Italian, and Spanish quarterly (seasonally adjusted) data for consumption, investment, money balances, inflation and the interest rate. While French, German, and Italian time series

\footnotetext{
${ }^{1}$ Therefore, we implement Christopher Sims' hybrid optimization algorithm „csminwel“, which combines the derivative-based BFGS method with a simplex algorithm. The „csminwel“ program is available at http://sims.princeton.edu/yftp/optimize/.
} 
data run from 1980:Q1 to 2008:Q3, we decided to follow Burrriel et al. (2010) and drop the data before 1987:Q1 for Spain because the changes in the structure of the Spanish economy were too substantial in the early eighties. Consumption and investment are measured by real personal consumption and real gross fixed capital formation in per capita terms. Real money balances are constructed by dividing the monetary aggregate M3 (again per capita) by the consumer price index that is also used for our measure of inflation. The interest rate is measured by the three month money market rate. The data sources are detailed in the appendix.

Following Fagan, Henry and Mestre (2005), we deal with the break in the series for Germany due to re-unification by re-scaling the West German series for consumption, investment and money prior to re-unification by the ratio of the values for West Germany and Germany at re-unification. The time series for (logs of) consumption, investment and M3 are detrended using the Hodrick-Prescott (H-P) filter. ${ }^{2}$

Despite its relative simplicity, the model contains a large number of parameters that are difficult to estimate precisely on only five time series. Hence, a number of parameters had to be fixed prior to estimation. More specifically, $\eta$ is set to 1.5 which implies that the representative household's labor supply in the steady state amounts to one-third of its time. In addition, the depreciation rate $\delta$ is set to 0.025 , corresponding to an annual depreciation rate of about 10 percent and $\theta$ is fixed at 6 , implying a steady state markup of prices over marginal cost of 20 percent. Lastly, we set the elasticities of output with respect to capital of each country equal to their respective average capital income share, calculated from OECD data. The steady state money growth rate of each country is set equal to the average rate of inflation for the whole sample under consideration.

\section{Estimating the Set of Stable Parameters: The ESS Procedure}

In this section we outline the ESS („Estimate of Set of Stable parameters“) procedure developed by Inoue and Rossi (2011), that allows to identify the subset of parameters of a model that are stable over time. They propose the following recursive procedure. First, test the joint null hypothesis that all parameters are stable, using a consistent

\footnotetext{
${ }^{2}$ To facilitate the process of parameter estimation, we follow DeJong and Dave (2007, Chapter 11.2.5) and perform further data alignment by scaling the filtered series using their (relative) means.
} 
test for structural breaks. Following Inoue and Rossi, we employ Andrews' (1993) QLR stability test. If the null is not rejected, then all the parameters belong to the set of stable parameters. If it is, the p-values of the individual test statistics are calculated in order to test whether each of the parameters is stable. Then the parameter with the lowest p-value is eliminated from the set of stable parameters, since this is the one that is most likely to be unstable. Second, it is tested whether the remaining parameters are jointly stable. If they are, then the set of stable parameters includes those parameters; otherwise, eliminate the parameter with the second lowest p-value from the set, and continue this procedure until the joint test on the remaining parameters does not reject stability.

Two specific features of the ESS procedure have to be emphasized:

(i) The individual tests do not rely on the assumption that the other parameters are constant over time. If these parameters are in fact time-varying, a "one at a time approach" might lead to invalid results.

(ii) The ESS approach overcomes the problem of size distortions, which arises "... in existing tests for structural breaks when used repeatedly to test structural changes in more than one subset of parameters" (Inoue and Rossi, 2011, p. 1203). ${ }^{3}$

\section{Results}

\subsection{Full Sample Estimates}

Here we first report the estimates for the whole sample before moving to the identification of parameter instabilities in section 5.2.

For each country table 1 presents the full sample maximum likelihood estimates of the parameters as well as the standard errors. The latter are computed using a parametric bootstrapping technique as in Cho and Moreno (2006) or Ireland (2007). According to Ireland (2007), this procedure simulates the estimated model for each country to generate 1000 samples of artificial data for real personal consumption, real gross fixed capital formation, real money balances, inflation, and the short term interest rate, each containing the same number of observations as the original samples of the

\footnotetext{
${ }^{3}$ For a more detailed description of the methodology, including a formal description of the algorithm and proofs, we refer to Inoue and Rossi (2011) as well as to their not-for-publication appendix; see http://econ.duke.edu/ brossi/NotforPublicationAppendixInoueRossi2009.pdf.
} 
four EMU countries, and then re-estimates the model 1000 times using these artificial data sets. For a detailed description of the parametric bootstrapping analysis we refer to Efron and Tibshirani (1993). The absolute value of the maximized log likelihood function is indicated by $|L|$.

\begin{tabular}{ccccccccc}
\hline \hline & \multicolumn{2}{c}{ France } & \multicolumn{2}{c}{ Germany } & \multicolumn{3}{c}{ Italy } & \multicolumn{2}{c}{ Spain } \\
Parameter & Estimate & Std. Error & Estimate & Std. Error & Estimate & Std. Error & Estimate & Std. Error \\
\hline$\beta$ & 0.9905 & 0.0112 & 0.9921 & 0.0014 & 0.9998 & 0.0410 & 0.9932 & 0.0277 \\
$\gamma$ & 0.0152 & 0.0091 & 0.0738 & 0.0116 & 0.0067 & 0.0157 & 0.0366 & 0.0334 \\
$\phi_{P}$ & 10.2132 & 2.7778 & 14.0161 & 0.4214 & 46.7997 & 14.2531 & 27.0936 & 6.9245 \\
$\phi_{K}$ & 26.5408 & 4.1028 & 30.2300 & 0.4423 & 35.4014 & 6.2435 & 20.5672 & 3.4103 \\
$\omega_{\mu}$ & 0.2009 & 0.0411 & 0.4362 & 0.0136 & 0.5647 & 0.1378 & 0.3163 & 0.0832 \\
$\omega_{\pi}$ & 0.9391 & 0.1491 & 1.6001 & 0.0037 & 1.0750 & 0.4163 & 0.8161 & 0.0901 \\
$\omega_{y}$ & -0.1011 & 0.0842 & -0.0025 & 0.0084 & -0.1673 & 0.1378 & -0.0711 & 0.0495 \\
$e$ & 4.1884 & 0.0202 & 2.9638 & 0.0002 & 3.7456 & 0.9409 & 4.3559 & 0.0056 \\
$z$ & 4214.3794 & 0.0001 & 4184.4742 & 0.0001 & 3189.9297 & 0.0080 & 1866.9879 & 0.0001 \\
$\rho_{a}$ & 0.9678 & 0.0357 & 0.9002 & 0.0056 & 0.8587 & 0.0782 & 0.9731 & 0.0221 \\
$\rho_{e}$ & 0.8778 & 0.0552 & 0.9001 & 0.0022 & 0.9877 & 0.0350 & 0.9360 & 0.0373 \\
$\rho_{x}$ & 0.9615 & 0.0381 & 0.9001 & 0.0011 & 0.9873 & 0.0386 & 0.9294 & 0.1063 \\
$\rho_{z}$ & 0.9125 & 0.0318 & 0.9005 & 0.0074 & 0.9871 & 0.0626 & 0.9210 & 0.0518 \\
$\rho_{v}$ & 0.4826 & 0.0096 & 0.2994 & 0.0083 & 0.1425 & 0.3356 & 0.3818 & 0.0121 \\
$\sigma_{a}$ & 0.0124 & 0.0012 & 0.0155 & 0.0011 & 0.0258 & 0.0178 & 0.0189 & 0.0020 \\
$\sigma_{e}$ & 0.0096 & 0.0007 & 0.0145 & 0.0014 & 0.0135 & 0.0030 & 0.0102 & 0.0003 \\
$\sigma_{x}$ & 0.0236 & 0.0201 & 0.0821 & 0.0082 & 0.2162 & 0.1450 & 0.0182 & 0.0094 \\
$\sigma_{z}$ & 0.0090 & 0.0012 & 0.0135 & 0.0010 & 0.0334 & 0.0052 & 0.0140 & 0.0014 \\
$\sigma_{v}$ & 0.0041 & 0.0007 & 0.0071 & 0.0005 & 0.0105 & 0.0028 & 0.0069 & 0.0008 \\
\hline$L \mid$ & 2195.2950 & & 2037.3376 & & 1891.2450 & & 1553.1251 \\
\hline \hline
\end{tabular}

Table 1: Maximum Likelihood Estimates: Full Samples.

To compare parameter estimates of the full samples across countries, we employ the Andrews and Fair (1988) Wald test. The Wald statistic can be written as

$$
W=\frac{\left(a_{i}-a_{j}\right)^{2}}{\sigma_{a_{i}}^{2}+\sigma_{a_{j}}^{2}},
$$

where $a$ and $\sigma_{a}$ denote the point estimate of a parameter and the associated bootstrapped standard deviation, respectively, for country $i, j \in\{$ France, Germany, Italy, Spain $\}, i \neq j$. The test statistic $W$ follows a $\chi^{2}(1)$ distribution under the null hypothesis of $a_{i}=a_{j}$. For a detailed discussion on the use of the bootstrap in hypothesis testing we refer to Cameron and Trivedi (2005). ${ }^{4}$

Turning to our results, we first note that the estimates for the discount factor $\beta$ are below unity, but exceed 0.99 for all of the four economies.

\footnotetext{
${ }^{4} \mathrm{~A}$ full set of the test statistics is available from the authors upon request.
} 
The money demand equation derived from the household's optimization problem implies an interest elasticity for real money holdings of $-\gamma$. We find small values of this elasticity with the correct sign for all regions, although the estimates for Italy and Spain turn out to be statistically insignificant. These results are in line with a large empirical literature detecting small interest rate elasticities of (broad) money demand (see Browne et al., 2005).

Next, we turn to the estimates for the rigidity parameters. For all countries, both the adjustment cost parameters for capital $\phi_{K}$ defined in subsection 2.2 and prices $\phi_{P}$ defined in subsection 2.3 are significant. The latter is significantly higher in Italy and Spain compared to France and Germany at the 5\% and 10\% level, respectively.

To gauge the plausibility of the price adjustment parameters, we adopt the approach of Keen and Wang (2007) and translate the estimates of $\phi_{P}$ into an average duration of quoted prices. For France and Germany we get an average duration of prices between six and seven months, respectively. The findings are supported for France by the results of Baudry et al. (2004) using French consumer price index (CPI) micro-data. Spain shows a higher degree of price stickiness implying an average of eight to nine months between price adjustments. This is in line with international micro evidence as reported in de Walque et al. (2006). In the case of Italy we find an average duration of consumer prices of ten to eleven months, which is consistent with the evidence from Italian CPI micro-data reported in Fabiani et al. (2010). Our findings are also confirmed by the result of analysis on consumer price changes conducted by Dhyne et al. (2006), who identify Italy to have the lowest incidence of price changes, whereas France shows the highest frequency of price changes among the four regions.

Turning to the monetary policy reaction function, our estimates of $\omega_{\pi}$ and $\omega_{\mu}$ are non-zero for all four countries, allowing at least for two possible interpretations of monetary policy (see subsection 2.4). Compared to France and Spain $\omega_{\pi}$ is significantly higher in Germany (at the 1\% level). This result might reflect the well-documented higher pre-occupation with inflation in this country. The point estimate of $\omega_{\pi}$ for Italy is also well below the estimate for Germany, although insignificantly so. Concerning the positive estimates of $\omega_{\mu}$ our results are consistent with the findings of Andrés et al. (2006) for the euro area. It is important to note that for each of the four countries the estimates of $\omega_{\mu}$ and $\omega_{\pi}$ sum up to a value greater than unity. Hence, the monetary policy rule is consistent with a unique rational expectations equilibrium (see Clarida et al., 2000). For all countries the estimates of $\omega_{y}$ are negative. However, they are insignificant, which makes it difficult to interpret this result as a hint for the presence 
of an endogenous money channel.

The estimates of $e$ and $z$ are not interesting from an economic policy point of view; they simply allow the steady state values of real balances and output in the model to match the average values of these variables in the data (see Ireland, 1997).

The estimates of $\rho_{a}, \rho_{e}, \rho_{x}, \rho_{z}$, and $\rho_{v}$ indicate a high persistence of the first four shocks, whereas the monetary policy shock is less persistent and even statistically insignificant for Italy. In the case of France, Germany, and Italy, the estimated standard deviations of the innovations are dominated by the ones of the investment shock, although the estimate of $\sigma_{x}$ turns out to be insignificant for Italy. This result is consistent with the findings of Justiniano et al. (2010) for the US. Hence, the marginal efficiency of investment shock is identified as the most important driver of business cycle fluctuations. For Spain the preference shock is the most volatile followed by the marginal efficiency of investment shock.

\subsection{Testing for Parameter Instability}

For each country tables $2-5$ report the parameter estimates and standard deviations in both sub-samples, while tables 6 - 9 show the p-values of the QLR test on individual parameters as well as the p-values at each step of the ESS procedure. The set of stable parameters at the $10 \%$ significance level is denoted by $\mathcal{S}$. To structure the following discussion, it is useful to divide the parameters into three groups:

(i) private sector parameters: $\beta, \gamma, \phi_{P}, \phi_{K}$;

(ii) monetary policy parameters: $\omega_{\mu}, \omega_{\pi}, \omega_{y}$;

(iii) shock parameters: $e, z, \rho_{a}, \rho_{e}, \rho_{x}, \rho_{z}, \rho_{v}, \sigma_{a}, \sigma_{e}, \sigma_{x}, \sigma_{z}$ and $\sigma_{v}$.

In the case of France, the QLR stability test indicates a significant break in 1994:Q3. Concerning the private sector parameters, table 6 reports instabilities of $\gamma$ and $\phi_{P}$. The estimates of $\gamma$ are lower in both sub-samples than in the full sample, the estimate for the 1980:Q1 to 1994:Q2 period is insignificant, however. Table 2 shows a sharp decline of the price rigidity parameter $\phi_{P}$. Further, we find significant changes in the monetary policy parameters $\omega_{y}$ and $\omega_{\pi}$, both increasing in absolute values. Concerning the shock 
parameters, the ESS procedure identifies only the technology shock to be stable with respect to both persistence and volatility. The direction of change in the persistence of the remaining shocks is ambiguous, while we find an overall decline in the volatilities $\sigma_{a}, \sigma_{e}, \sigma_{x}$, and $\sigma_{v}$.

For Germany we locate a break in 1994:Q2. ${ }^{5}$ As reported in table 7, the set of stable parameters $\mathcal{S}$ contains $\left(\sigma_{x}, \omega_{\mu}, \sigma_{e}, \omega_{\pi}, \rho_{e}, \rho_{a}, \rho_{z}, \omega_{y}, \rho_{x}\right)$. Most interestingly, we find monetary policy to be constant over time. This result suggests no discernible difference between the monetary policy conducted in the 1980:Q2 to 1994:Q1 period by the German Bundesbank and the 1994:Q2 to 2008:Q3 period, although the latter is affected by the inception of EMU and the monetary policy strategy of the ECB. Further, we find instabilities in all of the private sector parameters, as well as the persistence of the monetary policy shock and the volatilities of the preference shock $a_{t}$, the technology shock $z_{t}$ and the monetary policy shock $v_{t}$. Concerning the direction of change, only the volatility of the monetary policy shock increases, while the volatilities of the other shocks decline or stay constant over time.

We detect a significant break in 1994:Q4 for Italy. With respect to the private sector parameters, table 8 shows instabilities of $\gamma, \phi_{P}$, and $\phi_{K}$. According to table 4 the interest elasticity of money demand turns out to increase over time, while we find a significant decline in capital and price adjustment costs after the break. Concerning the monetary policy parameters, $\omega_{y}$ appears to be stable over time, whereas $\omega_{\mu}$ and $\omega_{\pi}$ both change significantly. More specifically, table 4 presents a sharp decline of $\omega_{\mu}$ and a substantial increase of $\omega_{\pi}$ in the 1994:Q4 to 2008:Q3 period. With exception of $\rho_{x}$, we find the persistence parameters to be unstable. While $\rho_{a}$ and $\rho_{v}$ increase, $\rho_{e}$ and $\rho_{z}$ turn out to decrease after the break. Regarding the volatilities of the five shocks, the ESS procedure identifies $\sigma_{a}$ and $\sigma_{e}$ to be stable, whereas $\sigma_{v}, \sigma_{x}$ and $\sigma_{z}$ decrease over time.

Turning to Spain, we find a significant break in 1998:Q1. Moreover, we detect instabilities in the private sector parameters $\left(\gamma, \phi_{P}, \phi_{K}\right)$, the monetary policy parameters $\left(\omega_{\mu}, \omega_{\pi}\right)$ and the shock parameters $\left(e, z, \rho_{z}, \rho_{v}, \sigma_{a}, \sigma_{e}, \sigma_{x}, \sigma_{z}\right.$ and $\left.\sigma_{v}\right)$. While $\omega_{\mu}$ decreases, $\omega_{\pi}$ is significantly higher after the break (see table 5 ). Furthermore, we observe a sharp decline in capital and price adjustment costs. Regarding the persistence of the technology shock and the money policy shock, table 5 shows a decrease in both, while the latter declines sharply after the break. With the exception of the money

\footnotetext{
${ }^{5}$ We cannot rule out a test bias due to the treatment of re-unification outlined in section 3 .
} 
demand shock, we also find a decrease in the volatilities of the shocks $a_{t}, x_{t}, z_{t}$, and $v_{t}$.

\section{Conclusions}

Despite some scepticism voiced in the literature, DSGE models became a cornerstone of modern macroeconometrics leading to a high acceptance both in academia and central banking; see Tovar (2009). Being firmly rooted in microeconomic foundations, this class of models is able to identify structural characteristics of economies that are not easily recovered from a necessarily parsimonious set of macroeconomic time series. Apart from their frequent use as a tool for the description and evaluation of monetary policy, DSGE models enable cross-country comparisons of such characteristics without having to resort to micro data (see Smets and Wouters, 2005).

In this paper, we apply a New Keynesian model to French, German, Italian, and Spanish data and formally test for parameter stability over time. Parameter instabilities are detected by making use of the ESS procedure („Estimate of Set of Stable parameters") developed by Inoue and Rossi (2011). This procedure allows to identify the parameters of the model that have changed at an unknown break date. In the cases of France, Germany, and Italy our results point to structural breaks in the mid-nineties after the beginning of the second stage of EMU, while the estimates for Spain show a significant break just before the start of the third stage of EMU in 1998. The most interesting result is that France, Italy, and Spain show significant changes in monetary policy behavior after the break dates, while monetary policy in Germany is found to be stable over time. Furthermore, France, Italy, and Spain show a significant decline in capital and price adjustment costs after the break. Moreover, we find at least four out of the five shocks to be either constant or declining after the break date for all economies under consideration.

On a methodological level, we could show that the use of DSGE models is able to shed some interesting light on the ongoing process of economic integration in Europe by allowing to look at the stability of structural and policy parameters both across countries and across time. This process yields numerous explanations for changes of allegedly „deep“ parameters. We empirically show that it is indeed important to take such potential changes into account and formally test for them. 


\section{Appendix: Data sources}

- France:

Real personal consumption: EUROSTAT

Gross fixed capital formation: EUROSTAT

Money balances (M3): Banque de France

Consumer price index: OECD

Interest rate (Pibor): OECD

Population: National Institute for Statistics and Economic Studies (INSEE)

- Germany:

Real personal consumption: Federal Statistics Office

Gross fixed capital formation: Federal Statistical Office

Money balances (M3): Deutsche Bundesbank

Consumer price index: OECD

Interest rate (Fibor): OECD

Population: Federal Statistical Office

- Italy:

Real personal consumption: Oxford Economics

Gross fixed capital formation: Oxford Economics

Money balances (M3): Oxford Economics

Consumer price index: Oxford Economics

Interest rate (three-month money market rate): Oxford Economics

Population: Oxford Economics

- Spain:

Real personal consumption: EUROSTAT

Gross fixed capital formation: EUROSTAT

Money balances (M3): Banco de España

Consumer price index: OECD

Interest rate (three-month money market rate): OECD

Population: EUROSTAT 


\section{References}

Andrews, Donald W. K. and Ray C. Fair, "Inference in Nonlinear Econometric Models with Structural Change," Review of Economic Studies, October 1988, 55 (184), 615-639.

Andrews, Donald W.K., "Tests for Parameter Instability and Structural Change with Unknown Change Point," Econometrica, July 1993, 61 (4), 821-856.

Andrés, Javier, J. David Lopéz-Salido, and Javier Vallés, "Money in an Estimated Business Cycle Model of the Euro Area," Economic Journal, April 2006, 116 (511), 457-477.

Angeloni, Ignazio and Michael Ehrmann, "The Euro and the Transmission of Monetary Policy," in Lawrence R. Klein, ed., Long-run growth and short-run stabilization: Essays in memory of Albert Ando, Elgar, 2006, pp. 161-206.

Baudry, Laurent, Hervé le Bihan, Patrick Sevestre, and Sylvie Tarrieu, "Price rigidity: Evidence from the French CPI micro-data," ECB Working Paper Series, August 2004, (384).

Beck, Günter W. and Axel A. Weber, "Inflation Rate Dispersion and Convergence in Monetary and Economic Unions: Lessons for the ECB," CFS Working Paper Series, November 2005, (2005/31).

Blanchard, Olivier J. and Charles M. Kahn, "The Solution of Linear Difference Models under Rational Expectations," Econometrica, July 1980, 48 (5), 1305-1311.

Browne, Frank, Gabriel Fagan, and Jerome Henry, "Money Demand in EU Countries: A Survey," Macroeconomics 0503004, EconWPA March 2005.

Burriel, Pablo, Jesús Fernández-Villaverde, and Juan Rubio-Ramírez, "MEDEA: A DSGE Model for the Spanish Economy," SERIEs - Journal of the Spanish Economic Association, March 2010, 1 (1), 175-243.

Cameron, A. Colin and Pravin K. Trivedi, Microeconometrics: Methods and applications, Cambridge University Press, 2005.

Canova, Fabio, Methods for applied macroeconomic research, Princeton University Press, 2007.

Cho, Seonghoon and Antonio Moreno, "A Small-Sample Study of the NewKeynesian Macro Model," Journal of Money, Credit and Banking, September 2006, 38 (6), 1461-1481.

Christensen, Ian and Ali Dib, "The Financial Accelerator in an Estimated New Keynesian Model," Review of Economic Dynamics, January 2008, 11 (1), 155-178. 
Clarida, Richard, Jordi Galí, and Mark Gertler, "Monetary Policy Rules and Macroeconomic Stability: Evidence and Some Theory," Quarterly Journal of Economics, February 2000, 115 (1), 147-180.

Cukierman, Alex and Francesco Lippi, "Labour Markets and Monetary Union: A Strategic Analysis," Economic Journal, July 2001, 111 (473), 541-565.

de Walque, Gregory, Frank Smets, and Raf Wouters, "Price Shocks in General Equilibrium: Alternative Specifications," CESifo Economic Studies, March 2006, 52 (1), 153-176.

DeJong, David N. and Chetan Dave, Structural macroeconometrics, Princeton University Press, 2007.

Dhyne, Emmanuel, Luis J. Álvarez, Hervé Le Bihan, Giovanni Veronese, Daniel Dias, Johannes Hoffmann, Nicole Jonker, Patrick Lünnemann, Fabio Rumler, and Jouko Vilmunen, "Price Changes in the Euro Area and the United States: Some Facts from Individual Consumer Price Data.," Journal of Economic Perspectives, 2006, 20 (2), 171-192.

DiCecio, Riccardo and Edward Nelson, "An Estimated DSGE Model for the United Kingdom," Federal Reserve Bank of St. Louis Review, July 2007, 89 (4), $215-231$.

Efron, Bradley and Robert J. Tibshirani, An introduction to the bootstrap, Chapman \& Hall/CRC, 1993.

European Commission, EMU@10: Successes and challenges after 10 years of economic and monetary union, Office for Official Publications of the European Communities, 2008.

Fabiani, Silvia, Angela Gattulli, Giovanni Veronese, and Roberto Sabbatini, "Price Adjustment in Italy: Evidence from Micro Producer and Consumer Prices," Managerial and Decision Economics, March 2010, 31 (2-3), 93-104.

Fagan, Gabriel, Jérôme Henry, and Ricardo Mestre, "An Area-Wide Model for the Euro Area," Economic Modelling, January 2005, 22 (1), 39-59.

Fernández-Villaverde, Jesús, "The Econometrics of DSGE Models," SERIEs - Journal of the Spanish Economic Association, March 2010, 1 (1), 3-49.

Fratzscher, Marcel and Livio Stracca, "The Political Economy Under Monetary Union: Has the Euro Made a Difference?," Economic Policy, 2009, 24 (58), 307 348.

Greenwood, Jeremy, Zvi Hercowitz, and Gregory W. Huffman, "Investment, Capacity Utilization, and the Real Business Cycle," American Economic Review, June 1988, 78 (3), 402-417. 
Hughes Hallett, Andrew and Christian Richter, "Has There Been Any Structural Convergence in the Transmission of European Monetary Policies?," International Economics and Economic Policy, July 2009, 6 (2), 85-101.

Inoue, Atsushi and Barbara Rossi, "Identifying the Sources of Instabilities in Macroeconomic Fluctuations," Review of Economics and Statistics, November 2011, 93 (4), 1186-1204.

Ireland, Peter N., "A Small, Structural, Quarterly Model for Monetary Policy Evaluation," Carnegie-Rochester Conference Series on Public Policy, December 1997, 47, 83-108.

_ , "Sticky-price Models of the Business Cycle: Specification and Stability," Journal of Monetary Economics, February 2001, 47 (1), 3-18.

_ , "Endogenous Money or Sticky Prices?," Journal of Monetary Economics, November 2003, 50 (8), 1623-1648.

_ , "Changes in the Federal Reserve's Inflation Target: Causes and Consequences," Journal of Money, Credit and Banking, December 2007, 39 (8), 1851-1882.

Jarocinski, Marek, "Responses to Monetary Policy Shocks in the East and the West of Europe: A Comparison," Journal of Applied Econometrics, August 2010, 25 (5), 833-868.

Jerger, Jürgen, "Socially Optimal Monetary Policy Institutions," European Journal of Political Economy, November 2002, 18 (4), 761-781.

Justiniano, Alejandro, Giorgio E. Primiceri, and Andrea Tambalotti, "Investment Shocks and Business Cycles," Journal of Monetary Economics, March 2010, 57 (2), 132-145.

Keen, Benjamin and Yongsheng Wang, "What is a Realistic Value for Price Adjustment Costs in New Keynesian Models?," Applied Economics Letters, September 2007, 14 (11), 789-793.

Lee, Jim, "Evaluating Monetary Policy of the Euro Area with Cross-Country Heterogeneity: Evidence from a New Keynesian Model," Economic Systems, 2009, 33 (4), $325-343$.

McCallum, Bennett T. and Edward Nelson, "An Optimizing IS-LM Specification for Monetary Policy and Business Cycle Analysis," Journal of Money, Credit and Banking, August 1999, 31 (3), 296-316.

Milani, Fabio, "Adaptive Learning and Macroeconomic Inertia in the Euro Area," Journal of Common Market Studies, June 2009, 47 (3), 579-599. 
Neiss, Katharine S. and Edward Nelson, "The Real-Interest-Rate Gap as an Inflation Indicator," Macroeconomic Dynamics, April 2003, 7 (2), 239-262.

Obstfeld, Maurice, "Exchange Rates and Adjustment: Perspectives from the New Open-Economy Macroeconomics," Monetary and Economic Studies, December 2002, 20 (S1), 23-46.

Popov, Alexander and Steven Ongena, "Interbank Market Integration, Loan Rates, and Firm Leverage," Journal of Banking 6 Finance, March 2011, 35 (3), $544-559$.

Reis, Ricardo, "Optimal Monetary Policy Rules in an Estimated Sticky-Information Model," American Economic Journal: Macroeconomics, July 2009, 1 (2), 1-28.

Rotemberg, Julio J., "Sticky Prices in the United States," Journal of Political Economy, December 1982, 90 (6), 1187-1211.

Smets, Frank and Raf Wouters, "Comparing Shocks and Frictions in US and Euro Area Business Cycles: A Bayesian DSGE Approach," Journal of Applied Econometrics, March 2005, 20 (2), 161-183.

Taylor, John B., "Discretion Versus Policy Rules in Practice," Carnegie-Rochester Conference Series on Public Policy, December 1993, 39 (1), 195-214.

Tovar, Camilo E., "DSGE Models and Central Banks," Economics: The Open-Access, Open-Assessment E-Journal, 2009, 3 (2009-16).

van Aarle, Bas, Harry Garretsen, and Cornelie van Moorsel, "Internal and External Transmissions of Monetary and Fiscal Policies in the EMU," Economic Systems, 2001, 25 (2), 127 - 148.

von Hagen, Jürgen, "Macroeconomic Consequences of the EMU," Empirica, December 1999, 26 (4), 359-374. 


\begin{tabular}{ccccc}
\hline \hline & \multicolumn{2}{c}{ 1980:Q1 $-1994: \mathrm{Q} 2$} & \multicolumn{2}{c}{ 1994:Q3 $-2008: \mathrm{Q} 3$} \\
Parameter & Estimate & Std. Error & Estimate & Std. Error \\
\hline$\beta$ & 0.9906 & 0.0013 & 0.9913 & 0.0024 \\
$\gamma$ & 0.0000 & 0.0007 & 0.0043 & 0.0014 \\
$\phi_{P}$ & 10.3880 & 0.5796 & 3.2691 & 0.3101 \\
$\phi_{K}$ & 30.0492 & 0.5400 & 28.8285 & 2.1778 \\
$\omega_{\mu}$ & 0.2980 & 0.0081 & 0.2792 & 0.0188 \\
$\omega_{\pi}$ & 1.1974 & 0.0095 & 1.4680 & 0.0807 \\
$\omega_{y}$ & -0.0075 & 0.0115 & -0.1417 & 0.0605 \\
$e$ & 4.4410 & 0.0006 & 4.3587 & 0.0115 \\
$z$ & 4185.6183 & 0.0001 & 4181.1612 & 0.0001 \\
$\rho_{a}$ & 0.8963 & 0.0065 & 0.8507 & 0.0137 \\
$\rho_{e}$ & 0.9000 & 0.0071 & 0.8132 & 0.0128 \\
$\rho_{x}$ & 0.9011 & 0.0078 & 0.9817 & 0.0067 \\
$\rho_{z}$ & 0.8995 & 0.0188 & 0.9222 & 0.0061 \\
$\rho_{v}$ & 0.4999 & 0.0076 & 0.1976 & 0.0249 \\
$\sigma_{a}$ & 0.0202 & 0.0004 & 0.0082 & 0.0002 \\
$\sigma_{e}$ & 0.0096 & 0.0001 & 0.0089 & 0.0001 \\
$\sigma_{x}$ & 0.0554 & 0.0069 & 0.0324 & 0.0021 \\
$\sigma_{z}$ & 0.0080 & 0.0003 & 0.0082 & 0.0002 \\
$\sigma_{v}$ & 0.0057 & 0.0001 & 0.0044 & 0.0003 \\
\hline \hline
\end{tabular}

Table 2: Maximum Likelihood Estimates: France. 


\begin{tabular}{ccccc}
\hline \hline & \multicolumn{2}{c}{$1980: \mathrm{Q} 1-1994: \mathrm{Q} 1$} & \multicolumn{2}{c}{ 1994:Q2 } \\
Parameter & Estimate & Std. Error & Estimate & Std. Error \\
\hline$\beta$ & 0.9918 & 0.0001 & 0.9925 & 0.0001 \\
$\gamma$ & 0.0739 & 0.0001 & 0.0751 & 0.0001 \\
$\phi_{P}$ & 13.9897 & 0.0131 & 14.0370 & 0.0159 \\
$\phi_{K}$ & 29.9417 & 0.1895 & 30.4771 & 0.1227 \\
$\omega_{\mu}$ & 0.4368 & 0.0006 & 0.4353 & 0.0009 \\
$\omega_{\pi}$ & 1.5998 & 0.0006 & 1.6005 & 0.0001 \\
$\omega_{y}$ & -0.0025 & 0.0007 & -0.0026 & 0.0008 \\
$e$ & 2.9639 & 0.0001 & 2.9635 & 0.0001 \\
$z$ & 4196.6065 & 0.0001 & 4160.1370 & 0.0001 \\
$\rho_{a}$ & 0.9000 & 0.0007 & 0.9002 & 0.0005 \\
$\rho_{e}$ & 0.9000 & 0.0005 & 0.9004 & 0.0004 \\
$\rho_{x}$ & 0.9001 & 0.0006 & 0.9001 & 0.0004 \\
$\rho_{z}$ & 0.9004 & 0.0007 & 0.9006 & 0.0004 \\
$\rho_{v}$ & 0.2999 & 0.0002 & 0.2984 & 0.0002 \\
$\sigma_{a}$ & 0.0185 & 0.0011 & 0.0107 & 0.0008 \\
$\sigma_{e}$ & 0.0150 & 0.0009 & 0.0135 & 0.0007 \\
$\sigma_{x}$ & 0.0852 & 0.0034 & 0.0784 & 0.0030 \\
$\sigma_{z}$ & 0.0161 & 0.0008 & 0.0109 & 0.0006 \\
$\sigma_{v}$ & 0.0063 & 0.0001 & 0.0076 & 0.0001 \\
\hline \hline
\end{tabular}

Table 3: Maximum Likelihood Estimates: Germany. 


\begin{tabular}{|c|c|c|c|c|}
\hline \multirow[b]{2}{*}{ Parameter } & \multicolumn{2}{|c|}{ 1980:Q1 - 1994:Q3 } & \multicolumn{2}{|c|}{ 1994:Q4 - 2008:Q3 } \\
\hline & Estimate & Std. Error & Estimate & Std. Error \\
\hline$\beta$ & 0.9992 & 0.0100 & 0.9975 & 0.0036 \\
\hline$\gamma$ & 0.0054 & 0.0057 & 0.0350 & 0.0057 \\
\hline$\phi_{P}$ & 64.6013 & 4.7897 & 31.7841 & 1.8189 \\
\hline$\phi_{K}$ & 33.1134 & 0.8700 & 14.5576 & 1.4126 \\
\hline$\omega_{\mu}$ & 0.6722 & 0.0287 & 0.0538 & 0.0096 \\
\hline$\omega_{\pi}$ & 0.8736 & 0.0287 & 1.6598 & 0.2561 \\
\hline$\omega_{y}$ & -0.1286 & 0.0302 & -0.1627 & 0.0832 \\
\hline$e$ & 3.9728 & 0.0855 & 3.2327 & 0.5237 \\
\hline$z$ & 3343.6115 & 0.0006 & 3336.9033 & 0.0013 \\
\hline$\rho_{a}$ & 0.8379 & 0.0108 & 0.9935 & 0.0142 \\
\hline$\rho_{e}$ & 0.9929 & 0.0093 & 0.9093 & 0.0119 \\
\hline$\rho_{x}$ & 0.9952 & 0.0085 & 0.9891 & 0.0077 \\
\hline$\rho_{z}$ & 0.9953 & 0.0195 & 0.8519 & 0.0062 \\
\hline$\rho_{v}$ & 0.0899 & 0.0662 & 0.5551 & 0.0022 \\
\hline$\sigma_{a}$ & 0.0291 & 0.0076 & 0.0119 & 0.0005 \\
\hline$\sigma_{e}$ & 0.0153 & 0.0021 & 0.0110 & 0.0001 \\
\hline$\sigma_{x}$ & 0.2501 & 0.0364 & 0.0192 & 0.0017 \\
\hline$\sigma_{z}$ & 0.0533 & 0.0017 & 0.0101 & 0.0003 \\
\hline$\sigma_{v}$ & 0.0128 & 0.0015 & 0.0034 & 0.0006 \\
\hline
\end{tabular}

Table 4: Maximum Likelihood Estimates: Italy. 


\begin{tabular}{|c|c|c|c|c|}
\hline \multirow[b]{2}{*}{ Parameter } & \multicolumn{2}{|c|}{ 1987:Q1 - 1997:Q4 } & \multicolumn{2}{|c|}{ 1998:Q1 - 2008:Q3 } \\
\hline & Estimate & Std. Error & Estimate & Std. Error \\
\hline$\beta$ & 0.9929 & 0.0067 & 0.9957 & 0.0020 \\
\hline$\gamma$ & 0.0189 & 0.0069 & 0.0518 & 0.0075 \\
\hline$\phi_{P}$ & 66.9756 & 3.5472 & 2.7164 & 0.3119 \\
\hline$\phi_{K}$ & 26.8170 & 0.7038 & 7.4710 & 0.4382 \\
\hline$\omega_{\mu}$ & 0.4707 & 0.0313 & 0.2367 & 0.0171 \\
\hline$\omega_{\pi}$ & 0.6868 & 0.0339 & 1.2448 & 0.0480 \\
\hline$\omega_{y}$ & -0.0646 & 0.0098 & -0.1006 & 0.0140 \\
\hline$e$ & 4.6627 & 0.0034 & 4.1651 & 0.0035 \\
\hline$z$ & 1932.4221 & 0.0001 & 1771.8852 & 0.0001 \\
\hline$\rho_{a}$ & 0.9542 & 0.0123 & 0.9411 & 0.0147 \\
\hline$\rho_{e}$ & 0.9440 & 0.0098 & 0.9648 & 0.0071 \\
\hline$\rho_{x}$ & 0.9625 & 0.0142 & 0.9903 & 0.0122 \\
\hline$\rho_{z}$ & 0.9477 & 0.0122 & 0.7833 & 0.0173 \\
\hline$\rho_{v}$ & 0.4565 & 0.0027 & 0.0333 & 0.0025 \\
\hline$\sigma_{a}$ & 0.0235 & 0.0006 & 0.0079 & 0.0002 \\
\hline$\sigma_{e}$ & 0.0084 & 0.0001 & 0.0107 & 0.0002 \\
\hline$\sigma_{x}$ & 0.0389 & 0.0086 & 0.0083 & 0.0004 \\
\hline$\sigma_{z}$ & 0.0227 & 0.0008 & 0.0073 & 0.0002 \\
\hline$\sigma_{v}$ & 0.0071 & 0.0003 & 0.0054 & 0.0002 \\
\hline
\end{tabular}

Table 5: Maximum Likelihood Estimates: Spain. 


\begin{tabular}{ccc}
\hline \hline $\begin{array}{c}\text { Model } \\
\text { Parameters }\end{array}$ & $\begin{array}{c}\text { Individual } \\
\text { p-value }\end{array}$ & $\begin{array}{c}\text { ESS } \\
\text { p-value }\end{array}$ \\
\hline$z$ & 0 & 0 \\
$\sigma_{a}$ & 0 & 0 \\
$\rho_{v}$ & 0 & 0 \\
$\phi_{P}$ & 0 & 0 \\
$\rho_{x}$ & 0 & 0 \\
$e$ & 0 & 0 \\
$\rho_{e}$ & 0 & 0 \\
$\sigma_{v}$ & 0 & 0 \\
$\sigma_{e}$ & 0 & 0 \\
$\omega_{\pi}$ & 0.0503 & 0 \\
$\sigma_{x}$ & 0.0723 & 0 \\
$\rho_{a}$ & 0.1106 & 0 \\
$\gamma$ & 0.2181 & 0 \\
$\omega_{y}$ & 0.5459 & 0 \\
$\rho_{z}$ & 1 & 1 \\
$\omega_{\mu}$ & 1 & 1 \\
$\sigma_{z}$ & 1 & 1 \\
$\phi_{K}$ & 1 & 1 \\
$\beta$ & 1 & 1
\end{tabular}

Set of stable parameters (90\% probability level): $\mathcal{S}=\left\{\rho_{z}, \omega_{\mu}, \sigma_{z}, \phi_{K}, \beta\right\}$

Table 6: The table shows the p-values of Andrews'(1993) QLR test on individual parameters for France. In addition the set of stable parameters is reported as well as the p-values at each step of Inoue and Rossi's (2011) ESS procedure. 


\begin{tabular}{ccc}
\hline \hline $\begin{array}{c}\text { Model } \\
\text { Parameters }\end{array}$ & $\begin{array}{c}\text { Individual } \\
\text { p-value }\end{array}$ & $\begin{array}{c}\text { ESS } \\
\text { p-value }\end{array}$ \\
\hline$z$ & 0 & 0 \\
$\gamma$ & 0 & 0 \\
$\sigma_{v}$ & 0 & 0 \\
$\beta$ & 0 & 0 \\
$e$ & 0 & 0 \\
$\sigma_{a}$ & 0 & 0 \\
$\rho_{v}$ & 0 & 0 \\
$\sigma_{z}$ & 0 & 0 \\
$\phi_{K}$ & 0.4175 & 0 \\
$\phi_{P}$ & 0.4615 & 0 \\
$\sigma_{x}$ & 1 & 1 \\
$\omega_{\mu}$ & 1 & 0.8630 \\
$\sigma_{e}$ & 1 & 0.7592 \\
$\omega_{\pi}$ & 1 & 1 \\
$\rho_{e}$ & 1 & 1 \\
$\rho_{a}$ & 1 & 1 \\
$\rho_{z}$ & 1 & 1 \\
$\omega_{y}$ & 1 & 1 \\
$\rho_{x}$ & 1 & 1
\end{tabular}

Set of stable parameters (90\% probability level): $\mathcal{S}=\left\{\sigma_{x}, \omega_{\mu}, \sigma_{e}, \omega_{\pi}, \rho_{e}, \rho_{a}, \rho_{z}, \omega_{y}, \rho_{x}\right\}$

Table 7: The table shows the p-values of Andrews'(1993) QLR test on individual parameters for Germany. In addition the set of stable parameters is reported as well as the p-values at each step of Inoue and Rossi's (2011) ESS procedure. 


\begin{tabular}{ccc}
\hline \hline $\begin{array}{c}\text { Model } \\
\text { Parameters }\end{array}$ & $\begin{array}{c}\text { Individual } \\
\text { p-value }\end{array}$ & $\begin{array}{c}\text { ESS } \\
\text { p-value }\end{array}$ \\
\hline$z$ & 0 & 0 \\
$\sigma_{z}$ & 0 & 0 \\
$\omega_{\mu}$ & 0 & 0 \\
$\phi_{K}$ & 0 & 0 \\
$\rho_{a}$ & 0 & 0 \\
$\rho_{v}$ & 0 & 0 \\
$\rho_{z}$ & 0 & 0 \\
$\phi_{P}$ & 0 & 0 \\
$\sigma_{x}$ & 0 & 0 \\
$\sigma_{v}$ & 0 & 0 \\
$\rho_{e}$ & 0 & 0 \\
$\gamma$ & 0.0180 & 0 \\
$\omega_{\pi}$ & 0.1498 & 0 \\
$\sigma_{a}$ & 0.4892 & 0.6207 \\
$\sigma_{e}$ & 0.6370 & 0.7320 \\
$e$ & 1 & 1 \\
$\rho_{x}$ & 1 & 1 \\
$\omega_{y}$ & 1 & 1 \\
$\beta$ & 1 & 1
\end{tabular}

Set of stable parameters (90\% probability level): $\mathcal{S}=\left\{\sigma_{a}, \sigma_{e}, e, \rho_{x}, \omega_{y}, \beta\right\}$

Table 8: The table shows the p-values of Andrews'(1993) QLR test on individual parameters for Italy. In addition the set of stable parameters is reported as well as the p-values at each step of Inoue and Rossi's (2011) ESS procedure. 


\begin{tabular}{ccc}
\hline \hline $\begin{array}{c}\text { Model } \\
\text { Parameters }\end{array}$ & $\begin{array}{c}\text { Individual } \\
\text { p-value }\end{array}$ & $\begin{array}{c}\text { ESS } \\
\text { p-value }\end{array}$ \\
\hline$z$ & 0 & 0 \\
$\rho_{v}$ & 0 & 0 \\
$e$ & 0 & 0 \\
$\sigma_{a}$ & 0 & 0 \\
$\phi_{K}$ & 0 & 0 \\
$\sigma_{z}$ & 0 & 0 \\
$\phi_{P}$ & 0 & 0 \\
$\sigma_{e}$ & 0 & 0 \\
$\omega_{\pi}$ & 0 & 0 \\
$\rho_{z}$ & 0 & 0 \\
$\omega_{\mu}$ & 0 & 0 \\
$\sigma_{v}$ & 0 & 0 \\
$\sigma_{x}$ & 0.0249 & 0 \\
$\gamma$ & 0.0066 & 0 \\
$\omega_{y}$ & 0.5959 & 0.6288 \\
$\rho_{e}$ & 0.8332 & 1 \\
$\rho_{x}$ & 1 & 1 \\
$\rho_{a}$ & 1 & 1 \\
$\beta$ & 1 & 1
\end{tabular}

Set of stable parameters (90\% probability level): $\mathcal{S}=\left\{\omega_{y}, \rho_{e}, \rho_{x}, \rho_{a}, \beta\right\}$

Table 9: The table shows the p-values of Andrews'(1993) QLR test on individual parameters for Spain. In addition the set of stable parameters is reported as well as the p-values at each step of Inoue and Rossi's (2011) ESS procedure. 